\title{
Occupational Health and Safety Challenges at the Examinations Unit of the College of Distance Education (CoDE), University of Cape Coast (UCC): A Descriptive Analysis
}

\author{
Matthew Quaidoo $^{1 *} \quad$ Isaac Eliot Nyieku ${ }^{2} \quad$ Kenneth Ebo Owuyaw ${ }^{3}$ \\ 1.Examinations Unit, College of Distance Education, University of Cape Coast, PMB, Cape Coast, Ghana \\ 2.Office of the College Registrar, College of Distance Education, University of Cape Coast, PMB, Cape Coast, \\ Ghana \\ 3.Student Records Management Unit, College of Distance Education, University of Cape Coast, PMB, Cape \\ Coast, Ghana
}

\begin{abstract}
Occupational health and safety (OHS) is a major issue of concern in higher educational settings especially due to the large volumes of printing during examinations. The purpose of this study is to assess the OHS practices at the Examinations Unit of CoDE and the challenges thereof. In a mixed method framework, the study uses descriptive survey research design to analyse the OHS issues. Stratified and purposive sampling techniques are used to select 106 respondents from a total population of 180 for the study. Semi-structured questionnaire is used to collect quantitative data which are analysed using frequency counts, percentages and mean of means while interview guide is employed to solicit qualitative responses which are transcribed and thematically analysed. The study reveals that most respondents (about 93 percent) are not aware of OHS policies being formulated and enforced at the workplace. About the same number of respondents are unaware of relevant provisions in the Workmen's Compensation Act 1987 (PNDCL 187) and Ghana Labour Act, 2003 (Act 651). As a result of unsatisfactory OHS practices and non-existing policies/regulations, respondents are exposed to numerous forms of hazards: safety, biological, ergonomic, physical, mechanical and psychological. The study recommends that management should initiate action to formulate and implement an OHS policy; invest in OHS performance; organise sensitisation workshops for staff and evaluate the policy implementation process periodically.
\end{abstract}

Keywords: Occupational Health and Safety, Examinations Unit, College of Distance Education, University of Cape Coast

DOI: $10.7176 / \mathrm{JEP} / 12-36-06$

Publication date: December $31^{\text {st }} 2021$

\section{Introduction}

Occupational Health and Safety (OHS) is a multidisciplinary phenomenon that deals with the safety, health and welfare of employees and promotes a safe and stimulating work environment (Wambulwa et al., 2018; Lim, 2012). Employers are bound by the constitution and relevant local and international laws to ensure the safety and health of employees. In addition to providing a satisfying work environment and healthy workplace concept, adherence to occupational safety and health regulations enhances employee work satisfaction and positive work outcomes (Perera, 2019; Oluoch, 2017). Effective management of health and safety at the workplace usually influences significantly and positively organisational commitment and productivity; impacts workers attitude positively towards work and gives them a more positive impression about their health and security (Umugwaneza, Nkechi \& Mugabe, 2019; Kaynak et al., 2016; Yeh, 2014; DeJoy et al., 2010; Ward et al., 2008). It is further asserted that organisations that invest massively in safety management system and practices are better placed to promote occupational safety, reduce/prevent job-related accidents, and improve employee as well as organisational performance (Wambulwa et al., 2018; Wachter \&Yorio, 2014; Dwomoh et al., 2013; and Oxenburgh et al., 2010).

When management takes care of employees by providing a safer and more secured working conditions, it gives a good signal of positive management of OHS system at the workplace. The associated benefits are manifold including improved staff morale, low stress, reduced mental and physical trauma, improved health, reduced absenteeism, reduced injuries and illnesses, reduced medical expenses as well as increased job satisfaction. These variables positively affect performance of employees and leads to increase in productivity (Dwomoh et al., 2013; Ward et al., 2008). Health and safety policies are part of the framework for effective health and safety management which invariably help to eliminate or reduce the risks of workplace illness or injury. A well formulated health and safety policy outlines management duties and intention to provide a safe and healthy workplace. It equally spells out the health and safety goals of a workplace (Oluoch, 2017). In general, occupational health and safety policies contain programmes and practices that seek to maintain and promote workers' health and working capacity; improve working environment; develop work organisations and working cultures; and create a positive social climate conducive to employee safety and health as well as productivity (Wambulwa, Makokha, \& Namusonge, 2018). According to Kaynak et al. (2016), a comprehensive OHS system mainly comprises Occupational Hazards 
Prevention (OHP), Safety Procedures and Risk Management (SPRM), Organisational Safety Support (OSS), Firstaid Supports and Training (FAST) as well as Safety and Health Rules (SAHR).

This study is significant because it provides the bases for the formulation and implementation of effective occupational health and safety policies to improve OHS practices at the Examinations Unit of CoDE. Additionally, it aims at providing the opportunity for employees and employers to identify their respective roles in health and safety issues at the College in order to improve OHS performance. It is also intended to draw the attention of staff to occupational health hazards and risks, make them aware of their OHS rights and the need to be informed about relevant local and international OHS-related legislation.

\section{Statement of the Problem}

Occupational Health and Safety (OHS) is a major issue of concern for all organisations, irrespective of the sector. The educational sector has its own share of OHS risk exposures. A significant share of these health risks and hazards in the educational sector emanates from huge volumes of printing during examinations. De Koster et al. (2011) assert that organisations that invest in safety practices and programmes/policies are well able to reduce occupational accidents and associated costs, thereby enhancing their safety performances and productivity. However, the critical question is, do educational institutions invest adequately in OHS to reduce accidents, injuries, physical and emotional stress together with other occupational hazards while promoting positive work outcomes? There is a plethora of empirical literature that focus on the effect of OHS practices/measures on employee or organisational performance in diverse sectors. Gbadago et al. (2017) study the impact of occupational health and safety measures on employee performance at the South Tongu District Hospital of Ghana, and find that adequate enforcement of the OHS measures of the hospital positively impact the performance of staff. Moreover, Wambulwa et al. (2018) employ a regression model to examine the effect of occupational safety and health on organisational performance at Nzoia Water in Trans-Nzoia County in Kenya, and conclude that accident reduction enhances organisational growth, survival as well as performance. These and many related literature are fixated on OHS and performance nexus in several fields of endeavor. Research on OHS practices, challenges as well as performance seems very scarce in the printing and educational sectors, particularly in higher education institutions in Ghana and beyond. This presents a clear research gap worthy of investigation since huge volumes of printing in the educational sector accounts for a significant share of health risks and hazards as indicated earlier.

\section{Objectives of the Study}

The purpose of this paper is to examine the occupational health and safety challenges at the Examinations Unit of the College of Distance Education (CoDE), University of Cape Coast. The paper specifically seeks to:

1. ascertain whether an OHS policy has been formulated and implemented by CoDE-UCC;

2. assess employees' level of awareness of relevant provisions of the Ghana Labour Act, the Compensations Act and other OHS Policy frameworks;

3. identify the kinds of risks or hazards employees at the Examinations Unit are exposed to and the possible causes;

4. examine employees' perspectives on their OHS rights/responsibilities at the workplace and OHS roles/responsibilities of top management.

\section{Theoretical Framework}

According to Multiple Causation Theory and Ferrell's Human Factor Theory, there are multiple causes or contributory factors and even sub-causes of accidents that occur at the workplace. The former stresses behavioural factors such as improper attitude, lack of knowledge, lack of skills, environmental factors including improper guarding of hazardous work elements, degradation of equipment through unsafe procedures, among others. The latter recognises general causes of accidents including emotional state of the individual, physical and educational background, training and situational factors such as exposure to drugs, pollutants and job-related stressors as well as load on the individual. This load may include the difficulty of the task, negative or positive effects of the environment (noise, lighting, ventilation, vibration, dust, etc.) and even the risky nature of the task. The two OHS models are consistent regarding the extent to which environmental, and organisational factors together with human and individual characteristics influence unsafe acts which can affect health and safety. While these theories posit that accidents are ultimately caused by human error, they are more likely to be due to the combined effects of overload, inappropriate workplace design, ill-structured jobs, inadequate workforce, poorly serviced machines, lack of management programmes and policies, inappropriate response and activities including performing a task without the necessary training or misjudging the degree of risk involved with a particular task (Goetsch, 2015).

Accident/Incident Theory (AIT) partly lends credence to the aforementioned argument that error by humans may be linked to overload and ergonomic traps arising from the design of work stations; and decision to err (Goetsch, 2015). AIT posits that the OHS performance or failures of organisations is solely the responsibility of management. Thus, bringing to the fore management's role in the causation and prevention of accidents. Among 
other things, management contributes to OHS performance by establishing or implementing a comprehensive safety policy, clearly defining accountability, responsibilities and authorisation for safety actions as well as improvements, giving adequate attention to measuring, monitoring, investigations and corrective actions (Pillay, 2014). According to AIT, OHS onus for investment, formulation and implementation of policies squarely lies on management.

Like AIT, the Goal-Freedom Alertness Theory developed by Kerr (1950) highlights the role of employers and management in ensuring safe work conditions and environment. This theory underscores that safe work performance is the result of psychologically rewarding work environment. Under this theory, accidents are viewed as low-quality work behaviour occurring in an unrewarding psychological climate with low level of alertness. According to the theory, a rewarding psychological climate is one where workers are encouraged to participate, set sustainable goals and choose methods or safety programmes to attain those goals. Goal-Freedom Alertness Theory essentially states that management should let workers have well-defined goals and freedom to pursue them in a congenial and psychologically motivating /rewarding work environment. The result is a higher level of alertness and focus on the tasks at hand. In accordance with this theory, Heinrich et al. (1980) suggest that managers and supervisors can actively work to alleviate hazards in the work environment.

In the final analysis, this framework concludes that environmental and organisational job factors, together with human and individual characteristics influence unsafe acts which can have impact on the health and safety of the worker as well as productivity. Hence, the role of the individual in terms of compliance and management in terms of investment, formulation in addition to implementation of OHS policies and programmes are crucial to improving safety performance.

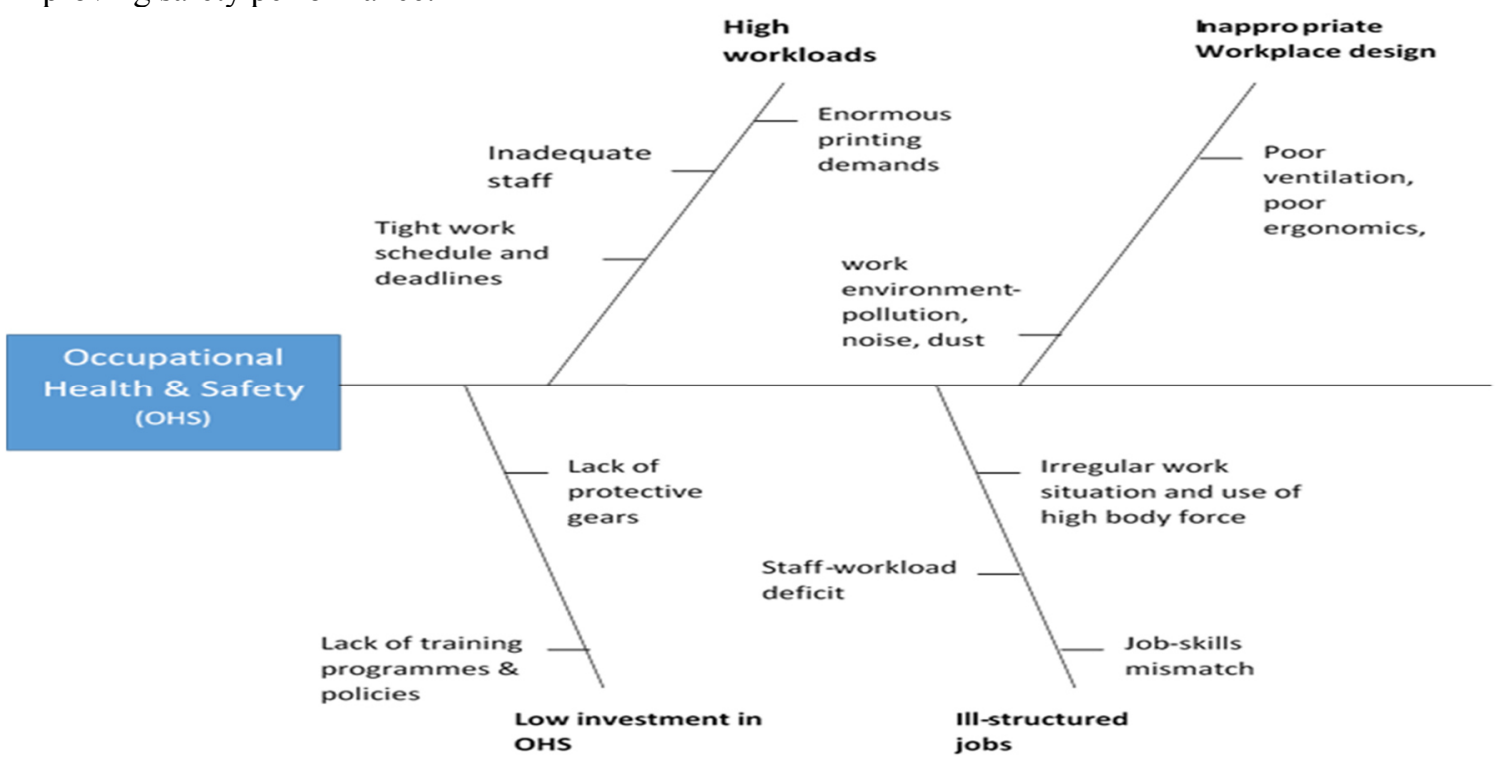

Figure 1: Conceptual Framework on Possible Causes \& Critical Factors

Source: Author's own construct, 2020

\subsection{Methodology and Analysis \\ 5.1 Profile of the Study Area}

The College of Distance Education (CoDE) is one of five (5) colleges in the University of Cape Coast (UCC). The College (formerly known as CCE) which started with initial student enrolment of 750 in 2001 and nine (9) study centres in nine (9) regions has seen an exponential increase in the number of study centres from nine (9) about 110 in the 2019/2020 academic year across the 16 regions of Ghana. Enrolment in 2019/2020 academic year stood at 4799, 7679 and 1250 for diploma, bachelor and master degrees respectively. There are currently four academic units in CoDE that run programmes in Arts and Social Sciences, Mathematics, Science \& ICT, Business Studies and Education Studies. Currently, CoDE runs about 40 programmes and almost 300 courses at the undergraduate level per semester. In a typical first semester, CoDE runs various types of examinations including Quizzes $1 \& 2$, Resit Exams ( $1 \&$ 2), End-of- Semester Exams $(1 \& 2)$ and Mature Entrance Exams (MEE). With the exception of MEE, same categories of examination are managed and coordinated by the Examinations Unit of CoDE in second semester. In dual mode distance institutions like CoDE), printing and marking of examination questions are usually intense because of the wide coverage. The Examinations Unit compiles and formats questions, oversees moderation of questions, prints and packages questions for about 300 courses every second semester at the undergraduate level. It also processes and prints volumes of postgraduate question papers. The Unit has 10 core staff and nine (9) national service persons. It engages over 150 national service personnel for marking of quizzes 
scripts and checking of marked end-of-semester examination scripts. More than 500 Chief Examiners, Team Leaders and Assistant Examiners are also engaged by the Unit at the end of each semester to mark end-of-semester scripts. The enormous printing during examinations culminates in significant occupational risks and hazards for staff engaged in such an activity.

It is noteworthy that about nine (9) national service persons assigned to the Examinations Unit are responsible for preparing the printing room and organising printing materials. Again, for every examination type, they label about 5000 security envelopes and thousands of folders to facilitate bagging. After printing, they are also invited into the printing room to help lift and allocate bagged questions/scripts according to programmes, centres and regions. The larger national service group outside the Examinations Unit are usually engaged to sit for long hours marking and recording quizzes scores and checking marked end-of-semester as well as re-sit examinations scripts. Hence, the inclusion of national service personnel in this study as respondents is indispensable.

\subsection{Research Design}

The study employed a mixed approach by analysing data collected both qualitatively and quantitatively. It adopted a descriptive survey design because the researchers sought to assess the OHS situation at the Examinations Unit of CoDE. According to Keller and Warrack (2000), descriptive surveys depend on direct contact with those persons or a sample of those whose characteristics are relevant for a specific investigation. The use of the descriptive survey created the opportunity for the researchers to administer the questionnaire personally to respondents, ask in-depth and follow-up questions and to give the needed clarity. Descriptive research generally precedes explanatory research. Hence, this is an effective strategy for gathering information with high accuracy for the study.

\subsection{Population and Sampling Procedures}

The population of core examination staff and personnel engaged internally for examination-related activities was 180. This comprised 10 core exams staff (a senior member, six senior staff and three junior staff), three (3) management personnel of CoDE, one (1) expert each from the Welfare Section of the Directorate of Human Resource and Directorate of Health Services, 165 national service personnel including those assigned to the Examinations Unit. The sample was made up of 123 people. This is because according to Krejcie and Morgan (1970), a sample size of about 123 is appropriate for a population of 180 . Out of 123 sample, 102 respondents answered the questionnaire while 4 participated in the interview. Purposive sampling method was used to select the interviewees due to their knowledge and experience in the phenomenon of interest (Creswell \& Clark, 2011). The interviewees consisted of two (2) management personnel and one (1) key staff each from the Welfare Section of the Directorate of Human Resource and Directorate of University Health Services. Creswell (2005) posits that selecting a larger number of interviewees will result in superficial perspectives ..., hence the researchers were unable to provide in-depth picture. For the quantitative data, stratified sampling was used to select the respondents by rank/job role and other relevant characteristics. This was to ensure proportional representation as they exist in the population. Simple random sampling procedure was used to select respondents from the sub-groups which are: senior staff, junior staff, national service personnel in the College as well as those assigned to the Unit. Semistructured questionnaire was administered by the researchers in person and collected on the spot.

\subsection{Instrumentation and Data Collection Procedure}

Self-administered semi-structured questionnaire and interview schedule were used to collect relevant quantitative and qualitative data for this study. An observation of the OHS practices and processes of the Unit was also made. The design of the instruments was based on related literature. Furthermore, Likert scale was used with relevant range to allow collection of firsthand data, strictly adhering to code of ethics governing research.

\subsection{Validity and Reliability of the Instruments}

The validation process started from research instruments to data content. By way of establishing validity of the instrument, two (2) independent raters with considerable knowledge of the phenomenon and analysis of data were given the instruments for a thorough check. Remarks from the raters were favourable and no massive changes were made. To ascertain the content validity of the instrument, two (2) experts in health and printing/publishing sectors respectively were approached to scrutinize it. Moreover, pre-testing was conducted among three (3) staff of the Examinations Unit to check the internal consistency of the instrument. Reliability test was done by asking the interviewees to either confirm or deny their statements after each interview schedule.

\subsection{Data Analysis}

Quantitative data was analysed using descriptive statistics. Hence, data analysis involved computations of mean of means, frequencies and percentages as well as construction of tables. The mean of means is simply the mean of all of the means of several samples. By calculating the mean of the sample means, the researcher simply summed the means of all the samples and divided by the number of means. The mean of means concept is akin to the 
combined mean concept which is simply a weighted mean, where the weights are the size of each group or sample. Qualitative data was analysed thematically. Data was organised, broken into manageable units and synthesised to search for patterns and transcribed comments were attributed to individuals as explained by Merriam and Associates (2002). The qualitative analysis was focused by the open-ended questions asked and also by individual respondent, given their expertise or knowledge of the topic or question. The researcher identified themes or patterns and connections in the data and organized them into coherent categories. To give clear interpretation to the data, the themes and connections were used to explain the findings.

\subsection{Findings and Discussion}

6.1 Characteristics of Respondents

Three (3) of the core staff were female while five (5) were male. The average age of the core staff was 38 and work experience from 7 to 14 years. About $88 \%$ were married with at least two children. Two (2) male management personnel participated in the study. Averagely, the core staff had over 12 years of education majority of whom have had their postgraduate degrees while management personnel had eighteen or more years of education with postgraduate and professional charter qualifications. Ninety-four (94) national service personnel, with average age of 25 years, took part in the study and 55 of whom were male. Almost all of them have had their first degrees. About 64 of entire respondents were male while 42 were female.

\section{Gender of Respondents}

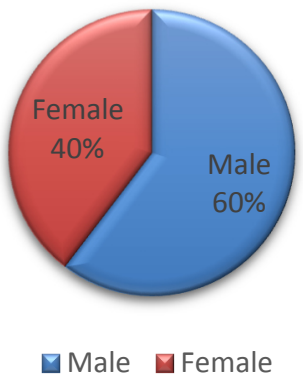

\subsection{Experiences with OHS issues at the Workplace}

In an attempt to shed light on respondents' experiences with OHS issues at the workplace, this study sought to assess their level of awareness about relevant OHS Policies, identify the nature of OHS hazards associated with their work and OHS management practices. The following tables present responses of the participants on the issues raised (especially core examinations unit staff and national service personnel of the College engaged for examination activities). A five-point Likert scale was employed to analyse the extent to which respondents agreed or disagreed on statements regarding OHS issues.

Table 1: Awareness of Occupational Safety and Health Polices/Regulations at the Workplace

\begin{tabular}{lllllllll}
\hline S/N & Questions & $\mathbf{1 ( S A )}$ & $\mathbf{2 ( A )}$ & $\mathbf{3 ( N )}$ & $\mathbf{4 ( D )}$ & $\mathbf{5 ( S D )}$ & Total & Mean \\
\hline 1. & $\begin{array}{l}\text { I am aware of the Workmen's } \\
\text { Compensation Act 1987 (PNDCL 187) } \\
\text { and relevant OHS portions of the Ghana }\end{array}$ & & & & & & & \\
Labour Act, 2003 (Act 651) that apply in \\
UCC.
\end{tabular}
Source: Field Survey, 2020

The data showed the level of awareness of the respondents of both internal and external OHS policies, regulations and procedures. Given the average mean score of about 4.3, it implies that most of the respondents (about 93 percent) were not aware of OHS policies being formulated and enforced at the workplace (CoDE-UCC). This had a higher mean score of 4.6 compared with the mean of means score. With a mean score of 4.1 , it stands to reason that a good number of the respondents lacked the requisite knowledge of the relevant provisions in the Workmen's Compensation Act 1987 (PNDCL 187) and Ghana Labour Act, 2003 (Act 651). Almost the same 
number of respondents were unaware of safe work procedures and regulations at the workplace. Considering the level of ignorance, it was difficult for respondents to follow safe work procedures and regulations and even assert their OHS rights. However, Umugwaneza, Nkechi, and Mugabe (2019) opine that employee awareness of the dangers of occupational health and safety minimizes workplace injuries and accidents to a considerable extent. Table 2: Exposure to Occupational Safety and Health Hazards and Nature of Hazards

\begin{tabular}{|c|c|c|c|c|c|c|c|c|}
\hline $\mathbf{S} / \mathbf{N}$ & Questions & 1(SD) & 2(D) & $3(N)$ & 4(A) & 5(SA) & Total & Mean \\
\hline 1. & $\begin{array}{l}\text { I have had accidents, injuries, illness or } \\
\text { other adverse health effects at the } \\
\text { workplace due to exposure to hazards and } \\
\text { risks. }\end{array}$ & $1(1)$ & $1(2)$ & $9(27)$ & $20(80)$ & $71(355)$ & 465 & 4.6 \\
\hline 2. & $\begin{array}{l}\text { I have had a change in the way my body } \\
\text { functions, grows or develops due to } \\
\text { exposure to hazards and risks at the } \\
\text { workplace. }\end{array}$ & $1(1)$ & $2(4)$ & $7(21)$ & $64(256)$ & $28(140)$ & 422 & 4.1 \\
\hline 3. & $\begin{array}{l}\text { I have had a condition resulting from } \\
\text { exposure to noise, vibration, stress, heat } \\
\text { or unseen dust/ release of compressed gas } \\
\text { and frequent bending of the waist, etc. }\end{array}$ & $0(0)$ & $2(4)$ & $8(42)$ & $63(252)$ & $29(145)$ & 425 & 4.2 \\
\hline 4. & $\begin{array}{l}\text { I am exposed to the following kinds of } \\
\text { hazards at the workplace. Safety [ ], } \\
\text { Biological [ ], Mechanical [ ] , } \\
\text { Ergonomic [ ] , Physical [ ], } \\
\text { Psychological [ ] }\end{array}$ & $0(0)$ & $0(0)$ & $7(21)$ & $22(88)$ & $73(365)$ & 474 & 4.7 \\
\hline
\end{tabular}

Source: Field Survey, 2020

Table 2 highlights two main issues: exposure to OHS hazards and nature of hazards. Issues on exposure to OHS hazards had average mean of 4.3 which presupposes that almost all the respondents, in one form or the other, have had accidents, injuries, illness or other adverse health effects at the workplace due to exposure to hazards and risks. Those that reported on conditions resulting from exposure to noise, vibration, stress, heat or unseen dust/release of compressed gas and frequent bending of the waist, inter alia, had a mean score of 4.2. Some respondents (about 90 percent) also indicated that they had had a change in the functioning of their bodies (waist problems) due to exposure to hazards and risks at the workplace.

Moreover, on the issue of nature of hazards, about 95 percent of total respondents described the type and nature of occupational hazards they encounter to include safety, biological, mechanical, ergonomic, physical and psychological confirming the finding of Gbadago et al. (2017). The mean score on nature of hazards was 4.7. In line with this, Ayalew and Demissie (2020) found that when management continuously follows up on every activity related to OHS programmes and implement effectively chemical, accidental and psychological hazard control programmes, organizational productivity is improved or enhanced.

Table 3: Possible Causes of Occupational Safety and Health Hazards and Challenges at the Examinations Unit

\begin{tabular}{|c|c|c|c|c|c|c|c|c|}
\hline $\mathbf{S} / \mathbf{N}$ & Questions & 1(SD) & 2(D) & $3(N)$ & $4(A)$ & 5(SA) & Total & Mean \\
\hline 1. & $\begin{array}{l}\text { My job requires the use of high body } \\
\text { force. }\end{array}$ & $0(0)$ & $0(0)$ & $3(9)$ & $69(276)$ & $30(150)$ & 435 & 4.3 \\
\hline 2. & $\begin{array}{l}\text { I have had accidents and injuries at } \\
\text { work due to job-skills mismatch. }\end{array}$ & $0(0)$ & $9(18)$ & $26(78)$ & $30(120)$ & $37(185)$ & 401 & 4.0 \\
\hline 3. & $\begin{array}{l}\text { Due to inappropriate work design, } \\
\text { there is a lot of noise, vibration, } \\
\text { stress, exposure to heat or unseen } \\
\text { dust and release of compressed gas. }\end{array}$ & $0(0)$ & $2(4)$ & $8(42)$ & $63(252)$ & $29(145)$ & 425 & 4.2 \\
\hline 4. & $\begin{array}{l}\text { There is bad ventilation at the } \\
\text { workplace. }\end{array}$ & $0(0)$ & $1(2)$ & $21(63)$ & $23(92)$ & $57(285)$ & 442 & 4.4 \\
\hline 5. & $\begin{array}{l}\text { I lift a lot of loads from the floor } \\
\text { more regularly. }\end{array}$ & $0(0)$ & $1(2)$ & $11(33)$ & $60(240)$ & $30(150)$ & 425 & 4.2 \\
\hline 6. & $\begin{array}{l}\text { There is poor lighting at the } \\
\text { workplace. }\end{array}$ & $24(24)$ & $69(138)$ & $9(27)$ & $0(0)$ & $0(0)$ & 189 & 1.9 \\
\hline 7. & $\begin{array}{l}\text { Enormous workload with tight } \\
\text { schedule and deadlines lead to stress }\end{array}$ & $0(0)$ & $1(2)$ & $3(9)$ & $17(68)$ & $81(405)$ & 484 & 4.7 \\
\hline
\end{tabular}




\begin{tabular}{|c|c|c|c|c|c|c|c|c|}
\hline $\mathbf{S} / \mathbf{N}$ & Questions & 1(SD) & 2(D) & $3(N)$ & $4(A)$ & 5(SA) & Total & Mean \\
\hline 8. & $\begin{array}{l}\text { Printing machines including smaller } \\
\text { ones used by NSPs are not regularly } \\
\text { serviced unless there is a fault. }\end{array}$ & $0(0)$ & $0(0)$ & $3(9)$ & $16(64)$ & $83(415)$ & 488 & 4.8 \\
\hline 9. & $\begin{array}{l}\text { I do not have the right and requisite } \\
\text { gears to protect myself from OHS } \\
\text { hazards and risks at the workplace. }\end{array}$ & $0(0)$ & $0(0)$ & $2(6)$ & $14(56)$ & $86(430)$ & 492 & 4.8 \\
\hline 10. & $\begin{array}{l}\text { I misjudge the degree of risk that } \\
\text { may be involved in my work or with } \\
\text { a particular task I perform. }\end{array}$ & $1(1)$ & $3(6)$ & $7(21)$ & $73(292)$ & $18(90)$ & 410 & 4.0 \\
\hline 11. & $\begin{array}{l}\text { I have performed my tasks without } \\
\text { the necessary OHS training. }\end{array}$ & $0(0)$ & $0(0)$ & $2(6)$ & $16(64)$ & $84(420)$ & 490 & 4.8 \\
\hline
\end{tabular}
Source: Field Survey, 2020

In Table 3, myriad of points were identified as possible causes of OHS hazards and challenges at the workplace, namely the use of high body force, job-skills mismatch, noise, vibration, stress, exposure to heat or unseen dust and release of compressed gas, poor ventilation, poor lighting, lifting of load on the floor, misjudgment of degree of risk, poorly serviced machines, lack of PPEs, lack of training, among others. With the mean of means of about 4.2, there is a resounding confirmation from respondents that OHS hazards and risks at the workplace are as a result of lack of training, lack of PPEs, poorly serviced machines and enormous workload. Relative to the average mean score, these issues had the highest mean of 4.8. Poor lighting is a minor issue as far as causes of OHS hazards at the workplace are concerned considering the mean score of 1.9. Heryati, Menzata Z and Afriyani (2019); Umugwaneza, Nkechi, and Mugabe (2019); Mwangi and Waiganjo (2017) establish that regular education and training, using an integrated approach, can promote positive attitude of employees towards occupational health and safety, mitigate or prevent workplace injuries, and also influence positively and dominantly employee performance. Umugwaneza, Nkechi, and Mugabe (2019) additionally support the finding that adequate provision of personal protective equipment reduce workplace injuries and accidents.

Table 4: Perspectives of Employees on their Occupational Safety and Health Rights/Responsibilities at the Workplace

\begin{tabular}{|c|c|c|c|c|c|c|c|c|}
\hline $\mathbf{S} / \mathbf{N}$ & Questions & 1(SD) & 2(D) & $3(N)$ & 4(A) & 5(SA) & Total & Mean \\
\hline 1. & $\begin{array}{l}\text { I have a right to know about any potential } \\
\text { hazard to which I may be exposed to at the } \\
\text { workplace. }\end{array}$ & $0(0)$ & $0(0)$ & $1(3)$ & $\begin{array}{l}16 \\
(64)\end{array}$ & $85(425)$ & 492 & 4.9 \\
\hline 2. & $\begin{array}{l}\text { I have the right to be part of the process of } \\
\text { identifying and resolving workplace health } \\
\text { and safety concerns. }\end{array}$ & $0(0)$ & $0(0)$ & $3(9)$ & $16(64)$ & $83(415)$ & 488 & 4.8 \\
\hline 3. & $\begin{array}{l}\text { I have the right to be informed on } \\
\text { occupational health and safety at the } \\
\text { workplace, given the nature of my work. }\end{array}$ & $0(0)$ & $0(0)$ & $2(6)$ & $16(64)$ & $84(420)$ & 490 & 4.8 \\
\hline 4. & $\begin{array}{l}\text { I have the responsibility to follow or } \\
\text { adhere to safe work practices, procedures } \\
\text { and regulations at the workplace. }\end{array}$ & $0(0)$ & $0(0)$ & $3(9)$ & $19(76)$ & $80(400)$ & 485 & 4.7 \\
\hline 5. & $\begin{array}{l}\text { Workers and employers must share the } \\
\text { responsibility for occupational health and } \\
\text { safety. }\end{array}$ & $0(0)$ & $0(0)$ & $7(21)$ & $8(32)$ & $87(435)$ & 488 & 4.8 \\
\hline
\end{tabular}

Source: Field Survey, 2020

Table 4 sheds light on OHS rights and responsibilities of respondents. With an average mean score of about 4.8 , respondents generally agreed that they have the right to be informed about OHS at the workplace including safe work practices, procedures and potential hazards. These coincide with the finding of Gbadago et al. (2017) that regular training on occupational health and safety at the workplace is critical. Additionally, about 98 percent of respondents argued that staff should be involved and recognised in the process of identifying and resolving workplace health and safety concerns. Relative to the mean of means, an overwhelming number of the respondents also affirmed that occupational health and safety is a shared responsibility for both workers and employers in terms of compliance, enforcement and investments. 
Table 5: Perspectives of Employees on Occupational Safety and Health Roles/Responsibilities of Top Management

\begin{tabular}{|c|c|c|c|c|c|c|c|c|}
\hline $\mathbf{S} / \mathbf{N}$ & Questions & 1(SA) & 2(A) & $3(N)$ & 4(D) & 5(SD) & Total & Mean \\
\hline 1. & $\begin{array}{l}\text { The employer/management enforces } \\
\text { health and safety regulations. }\end{array}$ & $0(0)$ & $1(2)$ & $4(12)$ & $28(112)$ & $69(345)$ & 471 & 4.6 \\
\hline 2. & $\begin{array}{l}\text { The employer/management corrects } \\
\text { unsafe acts and unsafe conditions. }\end{array}$ & $1(5)$ & $2(4)$ & $8(24)$ & $19(76)$ & $72(360)$ & 469 & 4.5 \\
\hline 3. & $\begin{array}{l}\text { The employer/management ensures that } \\
\text { only authorised, adequately trained } \\
\text { workers operate equipment. }\end{array}$ & $0(0)$ & $3(6)$ & $5(15)$ & $63(252)$ & $31(155)$ & 428 & 4.2 \\
\hline 4. & $\begin{array}{l}\text { The employer/management often ensures } \\
\text { the equipment are properly maintained or } \\
\text { serviced. }\end{array}$ & $3(3)$ & $3(6)$ & $3(9)$ & $83(332)$ & $10(65)$ & 415 & 4.1 \\
\hline 5. & $\begin{array}{l}\text { The employer/management promotes } \\
\text { safety awareness information among } \\
\text { staff. }\end{array}$ & $0(0)$ & $0(0)$ & $3(9)$ & $17(68)$ & $82(410)$ & 487 & 4.8 \\
\hline 6. & $\begin{array}{l}\text { The employer/management provides } \\
\text { medical and first aid facilities. }\end{array}$ & $0(0)$ & $0(0)$ & $0(0)$ & $19(76)$ & $83(415)$ & 491 & 4.8 \\
\hline 7. & $\begin{array}{l}\text { The employer/management ensures that } \\
\text { personal protective equipment (PPEs) is } \\
\text { available to all staff all the time. }\end{array}$ & $0(0)$ & $0(0)$ & $2(6)$ & $14(56)$ & $86(430)$ & 492 & 4.8 \\
\hline 8. & $\begin{array}{l}\text { There is an emergency response plan on } \\
\text { health and safety. }\end{array}$ & $0(0)$ & $0(0)$ & $0(0)$ & $16(64)$ & $86(430)$ & 494 & 4.8 \\
\hline 9. & $\begin{array}{l}\text { Assessments are usually done to identify } \\
\text { risks and hazards at the workplace. }\end{array}$ & $0(0)$ & $0(0)$ & $0(0)$ & $10(40)$ & $92(460)$ & 500 & 4.9 \\
\hline 10. & $\begin{array}{l}\text { Performance on health and safety is } \\
\text { regularly evaluated at our workplace. }\end{array}$ & $0(0)$ & $0(0)$ & $1(3)$ & $8(32)$ & $93(465)$ & 497 & 4.9 \\
\hline 11. & $\begin{array}{l}\text { There is a health and safety committee } \\
\text { constituted by staff which meets regularly } \\
\text { to review health and safety at the } \\
\text { workplace. }\end{array}$ & $0(0)$ & $0(0)$ & $0(0)$ & $4(16)$ & $98(490)$ & 506 & 5.0 \\
\hline
\end{tabular}

Source: Field Survey, 2020

In Table 5, analysis of the data reflected the perception of respondents that top management has not given the needed attention and commitment to improving OHS performance at the workplace in terms of enforcement of OHS regulations, maintenance of equipment, provision of personal protective equipment (PPEs) and first aid facilities for staff, promotion of safety awareness information, provision of OHS sensitisation training for staff, assessment of OHS performance at the work place, among others. With an average mean score of about 4.7, the general unsatisfactory responses make it quite evident. The highest mean score of 5.0 and 4.9 respectively, almost all the respondents agreed that the College should constitute a health and safety committee to evaluate OHS performance and assess OHS risks/hazards regularly. The need to provide PPEs, medical/first aid facilities, sensitisation and training had a mean score of 4.8. Mat et al. (2021) support the assertion that OHS management practices such as manager's/entrepreneur's commitment, safety training, worker's involvement in safety, safety communication, safety rules and procedures, and safety promotion policies correlate positively with safety performance in the organization.

6.3 Challenges faced by Management in improving OHS performance and steps taken by way of investments Some management personnel whom the onus lies to improve the work environment by promoting positive OHS practices did not mince words about the challenges. For example, one interviewee stated:

"CoDE has not been able to conduct an assessment of the OHS risks and hazards at the Examinations Unit and other critical sections. In fact, different categories of staff in almost all the sections are exposed to one risk or the other since they are deployed to the Centres to supervise examinations. For example, the OHS risks and hazards of the transport section cannot be overemphasised. It presupposes that CoDE, following a comprehensive OHS assessment of the critical units, would need an overarching policy guidelines to regulate and improve OHS practices. Hence, a tailor-made OHS policy framework for specific units would be difficult to develop. In short, we have not been able to improve the OHS practices and performance of the College due to lack of policy framework. I do not also think that the University has one but had relied on the Labour Act and other legislations anytime an injury or accident occurred at the workplace."

When asked about steps taken by management in terms of investment to improve the OHS practices and 
performance of the Unit/College, a management member indicated:

"Basically, any investment to improve the status quo means among other things engaging experts to conduct an assessment of the Examinations Unit and other critical units, procurement of PPEs, provision of first aid and training of staff on OHS issues. However, we are yet to initiate these steps since staff are increasingly becoming aware and asking critical questions."

\subsection{Formulation of OHS policy and the extent of implementation in UCC}

A social work expert with the Welfare Section of the Directorate of Human Resource, UCC was interviewed on the formulation and extent of implementation of OHS policy in the University, the existing procedures for handling cases of accidents/injuries arising out of OHS practices and the major challenges of the University/Directorate of Human Resource in developing policy guidelines on OHS. He had this to say:

"I should be emphatic that the University does not have and implements an all-encompassing OHS policy developed in-house though plans are far advanced to do so. For a long time, I can say to the best of my knowledge that, the University, through the Welfare Section of the Directorate of Human Resource, has been relying on the Workmen's Compensation Act 1987 (PNDCL 187) and relevant portions of the Ghana Labour Act, 2003 (Act 651) in resolving OHS issues, specifically accidents and injuries. However, there are codified procedures at the Welfare Section for workers to follow. Formulation of an all-encompassing policy on OHS has been difficult because of the diversity of the workforce in terms of the nature and types of work and multiplicity of units/section. It is actually a challenge to formulate one-size-fits-all OHS policy that addresses the myriad of OHS issues affecting all facets of the University, since there are peculiar and specialised units/sections. Hence, an OHS policy should be tailored to comprehensively address the OHS needs/issues of specific and specialised units/sections."

\subsection{Medical cases resulting out of poor OHS practices from CoDE and other Colleges and recommendations of health experts}

When an expert from the Directorate of University Health Services was interviewed on the medical cases resulting from OHS practices from CoDE and other Colleges/Sections, the following were the findings:

"A cursory look at the data on reported cases from the Exams Unit of CoDE and related places show the occurrence of minor musculoskeletal illnesses among staff involved in printing and other activities. The spine, lower back (waist problems), upper back and neck were most affected due to the nature of their work. Often, general body pains, headache, restlessness and stress are reported. I can attribute these conditions/injuries to frequent lifting of printing sheets, poor working positions (standing on the feet throughout the task and frequent bending), too much work and pressure due to the close time limes, among others".

The above confirms the responses of the core staff of the Exams Unit that workers face numerous hazards such as safety hazards, mechanical hazards, biological hazards, ergonomic, physical hazards and psychological hazards. Again, this corroborates the finding of Gbadago et al. (2017) in a study on the impact of occupational health and safety measures on employee performance.

In addition to the above insights, the health expert put across the following suggestions to improve the OHS condition at $\mathrm{CoDE}$ and the University at large:

"CoDE management should promote safety awareness information among staff. Management should provide medical and first aid facilities and also ensure that personal protective equipment (PPEs) are available to staff concerned at all times. There should be an emergency response plan on health and safety. Above all, staff of the Unit should have convenient leave arrangements to enable them rest properly".

\section{Conclusion}

On the basis of the findings, OHS practices and overall safety performance of the College needs to be improved. The study indicates that employees are unaware of OHS policy, regulations and safe work procedures at the workplace. Again, knowledge of relevant OHS provisions in the Workmen's Compensation Act 1987 (PNDCL 187) and Ghana Labour Act, 2003 (Act 651) among employees is relatively low. Consequently, most respondents, especially core Examinations Unit staff are prone to minor accidents, injuries and other adverse health effects at the workplace arising from exposure to noise, vibration, stress, heat or unseen dust/release of compressed gas and frequent bending of the waist and so forth. This is aggravated by a host of factors including the use of high body force, job-skills mismatch, poor ventilation, lifting of load on the floor, misjudgment of degree of risk, poorly serviced machines, lack of PPEs and lack of training. To mitigate the effects of occupational hazards and risks at the workplace namely safety, biological, mechanical, ergonomic, physical and psychological hazards, this study asserts that employees must be adequately informed and sensitized about safe work practices, procedures and potential hazards. The study also establishes the fact that OHS is a shared responsibility for both employers and 
employees. It highlights the need to frequently sensitize employees about OHS practices and procedures to ensure compliance. The findings indicate the need for employers/top management to improve the OHS performance at the College by ensuring policy formulation and enforcement, maintenance of equipment, provision of personal protective equipment (PPEs), provision of first aid facilities for staff, promotion of safety awareness information, provision of OHS sensitisation training for staff, assessment of OHS performance at the work place, constitution of health and safety committee, regular evaluation of OHS performance and periodic assessment of OHS risks/hazards.

\section{Recommendations}

Based on the findings and conclusions from the study, the following recommendations are made:

- Management, through the College Registrar and the Unit Coordinator should enforce conventional health and safety rules/regulations at the workplace.

- College Registrar, College Finance Officer and the Unit Coordinator should ensure the equipment for printing are properly maintained at regular interval.

- College Registrar and College Finance Officer should ensure that personal protective equipment (PPEs) are available for staff concerned at all times.

- College Registrar and the Unit Coordinator, on the advice of health expert, should provide medical and first aid facilities.

- Management, through the College Registrar and the Unit Coordinator should promote safety awareness information among staff by way of scheduled sensitisation training.

- College Registrar and Unit Coordinator should ensure comprehensive assessment is carried out to identify risks and hazards at the Unit.

- Management should initiate pragmatic steps to formulate a comprehensive OHS policy framework and regulations for the Unit and other critical sections to improve the safety performance of the College.

- Performance on health and safety, in terms of strict enforcement of policy and continued investments should be regularly evaluated by Management.

- College Registrar and Unit Coordinator could constitute health and safety committees for critical units to enable staff to meet regularly to review health and safety at the workplace and ultimately improve safety performance.

- Management should make conscious effort to redesign the workplace to consider issues of ergonomics, ventilation, etc. Management also needs to restructure jobs to address challenges regarding job-skills mismatch, staff workload deficit, etc. to promote work satisfaction among employees.

\section{References}

Ayalew, A., \& Demissie, Y. (2020). The Effect of Occupational Health And Safety Program On Organizational Productivity: In Case of Bahirdar Tannery Factory. International Journal of Scientific and Research Publications, 10(2), 779-798.

Creswell, J. W. (2005). Research Design: qualitative, quantitative, and mixed methods approaches ( $2^{\text {nd }}$ ed.). London: Sage Publications.

Creswell, J. W., \& Plano Clark, V. L. (2011). Designing and conducting mixed method research. $2^{\text {nd }}$ Sage; Thousand Oaks, CA.

DeJoy, D. M., Della, L. J., Vandenberg, R. J., \& Wilson, M. G. (2010). Making work safer: Testing a model of social exchange and safety management, Journal of Safety Research, 41, 163-171. http://dx.doi.org/10.1016/j.jsr.2010.02.001

De Koster, R. B. M., Stam, D., \& Balk, B. M. (2011). 'Accidents happen: The influence of safety-specific transformational leadership, safety consciousness, and hazard reducing systems on warehouse accidents'. Journal of Operations Management, 29(7-8), 753-765. http://dx.doi.org/10.1016/j.jom.2011.06.005

Dwomoh, G., Owusu, E. E., \& Addo, M. (2013). 'Impact of occupational health and safety policies on employees' performance in the Ghana's timber industry: Evidence from Lumber and Logs Limited'. International Journal of Education and Research, Vol. 1 No. 12 December 2013. ISSN: 2201-6333 (Print) ISSN: 22016740 (Online)

Gbadago, P., Amedome, S. N., \& Honyenuga, B. Q. (2017). 'The Impact of Occupational Health and Safety Measures on Employee Performance at the South Tongu District Hospital'. Global Journal of Medical Research: K Interdisciplinary, 17(5), 13-19

Goetsch, D. L. (2015). Occupational safety and health for technologists (8th edition). Sydney: Pearson, 2015.

Heryati, A., Menzata Z, R. A., \& Afriyani, F. (2019). The Impact of Occupational Health and Safety (OHS) Training and Compensation on Employees `Performance. International Journal of Advanced Science and Technology Vol. 28, No. 11, (2019), pp. 09-16

Jane, W. M. (2018). Influence of Occupational Health and Safety on Employees'performance in the Flower 
Industry in Kenya: A Case Study of Penta Flowers Limited, Thika Sub-County [Phd Thesis]. Jkuat-Cohred.

Kaynak, R., Toklu, A. T., Elci, M., \& Toklu, I. T. (2016). Effects of Occupational Health and Safety Practices on Organizational Commitment, Work Alienation, and Job Performance: Using the PLS-SEM Approach. International Journal of Business and Management, 11(5), 146-166

Lim, A. (2012). 'OHS management system: Three benefits for construction enterprise'. Retrieved on 12 trh April 2017 from www.artipot.com/ article-tags/ohs-management system.

Mat, R. C., Alias, W. N. I. W., Tan, I. H., Abdullah, Z. M., \& Zin, S. M. (2021). Conceptual Framework of Health and Safety Management Practices Affecting Safety Performance of Malaysian Bumiputera SMEs.

Merriam, S. B. \& Associates, (2002). Qualitative research in practice: Example for discussion and analysis. San Francisco, CA: Joseey-Bass.

Oluoch, I. (2017). Assessment of the Occupational Safety and Health Management Practices in Water Service Industry in Kisumu County Kenya. Unpublished master's dissertation, Jomo Kenyatta University of Agriculture and Technology. Kenya.

Perera, G. D. N. (2019). Occupational health and safety practice and job performance: Role of job satisfaction. Sri Lankan Journal of Human Resource Management, 9(1).

Pillay, M. (2014). 'Taking stock of zero harm: A review of theory on contemporary health and safety management in construction,' in CIB W099 International Health and Safety Conference, Lund, Sweden, 2014, pp. 75-85.

Umugwaneza, C., Nkechi, I. E., \& Mugabe, J. B. (2019). Effect of Workplace Safety and Health Practices on Employee Commitment and Performance in Steel Manufacturing Companies in Rwanda.

Wachter, J. K., \& Yorio, P. L. (2014). A system of safety management practices and worker engagement for reducing and preventing accidents: An empirical and theoretical investigation. Accident Analysis and Prevention, 68, 117-130. http://dx.doi.org/10.1016/j.aap.2013.07.029

Wambulwa, B. N., Makokha E. N., \& Namusonge, G. (2018). 'Effect of Occupational Safety and Health on Organizational Performance: A Case of Nzoia Water in Trans-Nzoia County'. European Journal of Business and Management, 10(11), 47-56

Ward, J., Haslam, C. \& Haslam, R. (2008). The Impact of Health and Safety Management on Organizations and their Staff. IOSH-UK: Loughborough University.

Yeh, Y. P. (2014). Exploring the impacts of employee advocacy on job satisfaction and organizational commitment: Case of Taiwanese airlines. Journal of Air Transport Management, 36, 94-100. http://dx.doi.org/10.1016/j.jairtraman.2014.01.002 